\title{
Hb Murcia (ק118(G19)His>GIn): A New Hemoglobin Variant Found in a Spanish Woman
}

\author{
Beatriz González Fernández (iD, M.S. ${ }^{1,2}$, José Bartolomé Nieto Campuzano 투, M.D. ${ }^{3}$, Dolores García Rocamora 무, M.D. ${ }^{4}$,

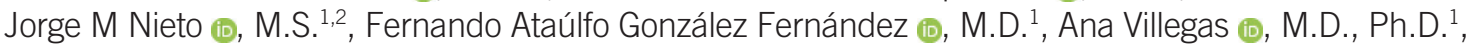 \\ Celina Benavente Cuesta (ib, M.D. ${ }^{1}$, and Paloma Ropero i, Ph.D. ${ }^{1,2}$ \\ ${ }^{1}$ Servicio de Hematología, Hospital Clínico San Carlos, Madrid, Spain; ${ }^{2}$ Instituto de Investigación Sanitaria Hospital Clínico San Carlos, Madrid, Spain; \\ ${ }^{3}$ Servicio de Hematología, Hospital Morales Meseguer, Murcia, Spain; ${ }^{4}$ Servicio de Bioquímica, Hospital Morales Meseguer, Murcia, Spain
}

\section{Dear Editor,}

Structural hemoglobinopathies are the most common monogenic disorders globally [1]. Most hemoglobin $(\mathrm{Hb})$ variants are clinically silent but can be identified during neonatal screening, in population studies, or during the quantification of glycated $\mathrm{Hb}$ (HbAlc) [2]. The presence of an Hb variant may interfere with $\mathrm{HbAlc}$ quantification.

We report a new $\mathrm{Hb}$ variant found in a 76-year-old Spanish woman from Murcia. The patient was scheduled to undergo cataract surgery in the left eye in February 2015. As part of preoperative examinations, patient's blood was collected in three $5 \mathrm{~mL}$ EDTAcoated tubes. In cation-exchange (CE)-HPLC in an automated glycohemoglobin analyzer (Bio-Rad D-100; VARIANT, Bio-Rad Laboratories, Hercules, CA, USA), falsely increased HbA1c levels were observed: $\mathrm{HbA} 1 \mathrm{c}$ level was detected as $7 \%$, whereas the actual level —measured by affinity chromatography —was $5 \%$. Although no other major peak in CE-HPLC suggestive of a variant was observed, the sample was sent to the hemoglobinopathies referral center at Hematology service, Erythropathology section, Hospital Clínico San Carlos de Madrid, to rule out interference due to a structural hemoglobinopathy. The study did not need approval by the Institutional Review Board, but informed consent was provided by the patient. Experiments were con- ducted according to the Declaration of Helsinki.

The patient's hematological findings were normal, with no anemia ( $\mathrm{Hb} 124 \mathrm{~g} / \mathrm{L}$ [reference range, 120-156 g/L]), no microcytosis (mean corpuscular volume $97.6 \mathrm{fL}$ [reference range, 81$98 \mathrm{fL}]$ ), no hypochromia (mean corpuscular $\mathrm{Hb} 30.7$ pg [reference range, 26-33 pg]), and a normal reticulocyte count (0.6\%); a peripheral blood smear did not show morphological abnormalities. $\mathrm{Hb}$ analysis by capillary zone electrophoresis (Sebia Capillarys Flex Sebia, Norcross, GA, USA) revealed no abnormal peaks (Fig. 1). However, chromatographic analysis by CE-HPLC using the $\beta$-thalassemia short program (VARIANT, Bio-Rad Laboratories) revealed the presence of an $\mathrm{Hb}$ variant at retention time 2.36 minutes, which accounted for $37.3 \%$ of the total $\mathrm{Hb}$. This variant eluted ahead of $\mathrm{HbAO}$, without full separation (Fig. 1). $\mathrm{HbA}_{2}$ and fetal $(\mathrm{HbF})$ levels measured by $\mathrm{CE}-\mathrm{HPLC}$ were normal ( $2.7 \%$ and $0.7 \%$ respectively). The variant was characterized by automatic sequencing of the $\beta$ globin gene (HBB) as previously described [3]. The sequencing results revealed a transversion of cytosine to guanine (CAC>CAG) in codon 118 of the third exon (Fig. 2), resulting in a missense variant with a glutamine instead of a histidine (HBB:C.354C>G; $\beta 118$ (G19) $\mathrm{His}>\mathrm{GIn}$ ). We named this variant "Hb Murcia" after the city where the patient lives.
Received: September 15, 2020

Revision received: October 14, 2020

Accepted: March 5, 2021

Corresponding author: Paloma Ropero. Ph.D.

Servicio de Hematología, Hospital Clínico San Carlos C/ Professor Martín Lagos s/n, 28040 Madrid, Spain

Tel: +34-91-3303321, Fax: +34-91-3303322

E-mail: paloma.ropero@salud.madrid.org

\section{(c) (i) (8)}

\section{(c) Korean Society for Laboratory Medicine}

This is an Open Access article distributed under the terms of the Creative Commons Attribution Non-Commercial License (https://creativecommons.org/licenses/by-nc/4.0) which permits unrestricted non-commercial use, distribution, and reproduction in any medium, provided the original work is properly cited. 

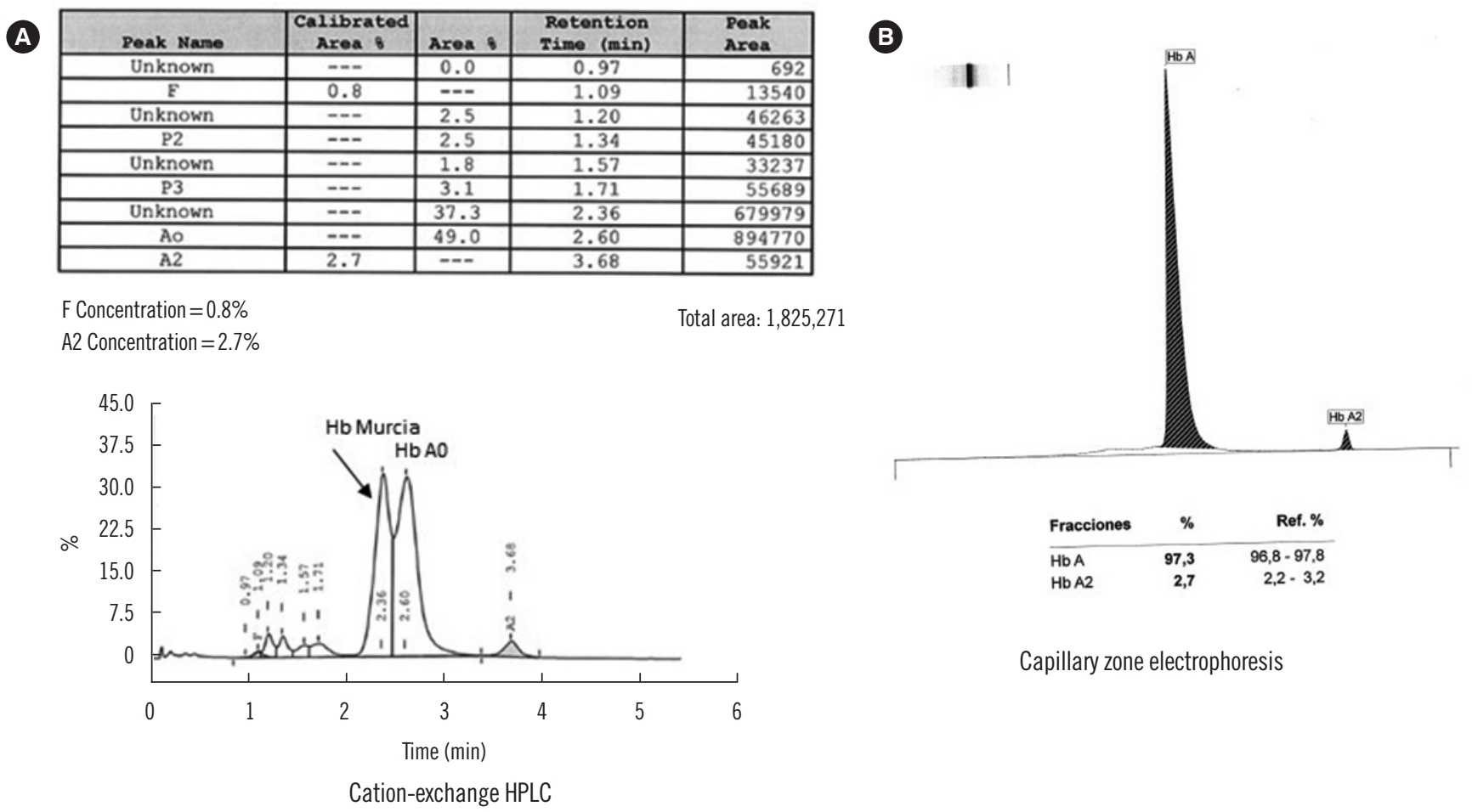

Capillary zone electrophoresis

Fig. 1. Analysis of hemoglobin using different methods. (A) Cation exchange HPLC with a Bio-Rad Variant II $\beta$-Thalassemia Short Program. $\mathrm{HbF}(0.8 \%), \mathrm{HbX}(37.3 \%), \mathrm{HbA}(49 \%)$, and $\mathrm{HbA}_{2}$ (2.7\%). (B) Capillary zone electrophoresis. HbA + HbX (97.3\%) and HbA2 (2.7\%). Abbreviation: $\mathrm{Hb}$, hemoglobin; Ref., reference range.

Some residues of the $\mathrm{C}, \mathrm{G}$, and $\mathrm{H}$ helices of $\mathrm{Hb}$ are a part of the $\alpha 1 \beta 1$ contact area. Most of these contacts are weak, noncovalent bonds, such as Van der Waals interactions and hydrogen bonds, although the latter have a less prominent role in $\alpha 1 \beta 1$ contact. These contacts form a rigid dimer, so that during $\mathrm{Hb}$ oxygenation and deoxygenation, movement in this area is extremely limited [1]. Therefore, any constitutional variation could give rise to structural modifications that can cause $\mathrm{Hb}$ precipitation in erythropoietic progenitors depending on the location of the residue within the helix, its participation in $\mathrm{Hb}$ functionality, and the characteristics of the residue. This, in turn, may cause ineffective erythropoiesis or hemolytic anemia. An example of these behaviors is $\mathrm{Hb}$ variants at position G19. Position 19 of the $G$ helix of the globin $\beta$ chain is occupied by residue 118 , a histidine. This residue is located externally in the three-dimensional protein structure and interacts with two residues of the $\alpha 1$ globin chain ( $\alpha 110$ alanine [G17] and $\alpha 114$ proline [GH2]) and one residue of the same $\beta$ globin chain (Glu $\beta 22$ [B4]) through hydrogen bonds [4]. At this position, five variants have been described: Hb P-Galveston, Hb Brent, Hb Tsukumi, Hb North York, and $\mathrm{Hb}$ Saitama. All these variants were detected incidentally through electrophoretic and chromatographic methods, as the mobility of $\mathrm{Hb}$ is altered due to modification of the surface charge when a positively charged polar amino acid, such as histidine, is substituted with a neutral or negatively charged one. The functional properties and stability of the resulting $\mathrm{Hb}$ have been studied for three of these variants. Hb Saitama leads to hemolytic anemia, as it has decreased affinity for oxygen and is unstable - probably because of the insertion of a proline, which tends to have a destabilizing effect on the chain [5]. By contrast, Hb PGalveston and $\mathrm{Hb}$ Tsukumi are functionally normal. The remaining variants, including the one reported here (Hb Murcia), have not been studied for functionality and stability. However, given the hematological profiles of the patients, both the stability and the functionality of hemoglobin are probably not altered and, therefore, these variants are not harmful, i.e., they are clinically silent [3, 6-8].

The redundancy of the genetic code is not the same for all amino acids; while leucine, serine, and arginine are encoded by six different codons, histidine is encoded by only two (CAT and $\mathrm{CAC}$ ). Accordingly, the probability of finding more variants is greater in the latter. Indeed, $\mathrm{Hb}$ Murcia is the sixth variant described at position $\beta 118$ (G19). All possible variants have been described, except the one that leads to a leucine substitution 


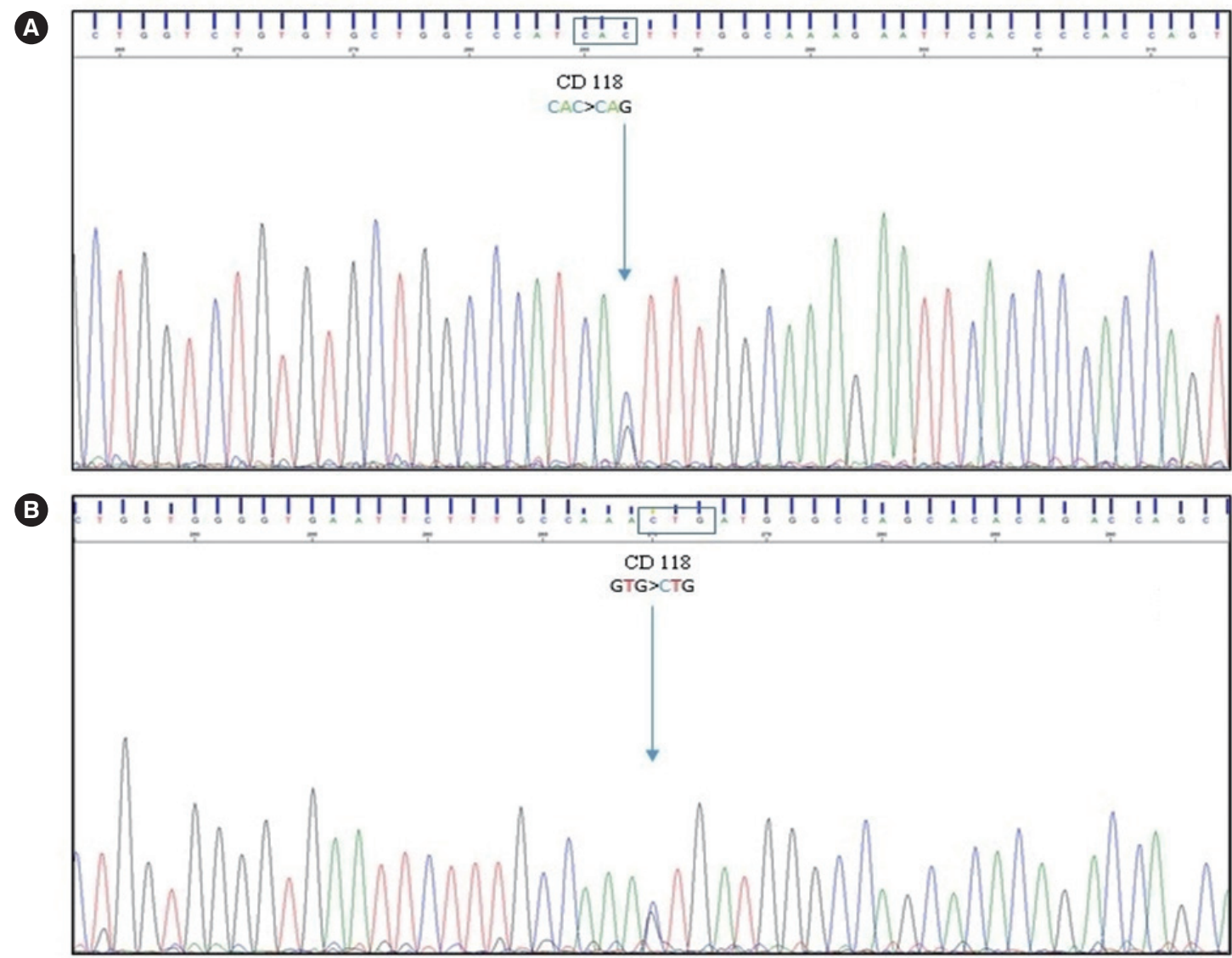

Fig. 2. Automated sequencing of the $\beta$ globin gene (CD118 of the third exon). (A) Direct sequence. Substitution of CAC $\rightarrow$ CA $\boldsymbol{G}$. (B) Reverse sequence. Substitution of GT $\boldsymbol{G} \rightarrow \mathrm{GTC}$. Abbreviation: $C D$, codon.

(CAC > CTC). Genetic coordinates of $H B B$ gene are given in the hg19 genome version. The nucleotide cytosine HBB:c.354C >G variant (transcript HBB [NM_000518.5C>G]) is highly conserved among primates and placental mammals, as evidenced by the value of +2.035 assigned in the 100 vertebrates Basewise Conservation by PhyloP (phyloP100wayAll), where positive values indicate evolutionary conservation of a nucleotide [9]. The variant chr11:5225688C $>\mathrm{G}(\beta 118(\mathrm{G} 19) \mathrm{His}>\mathrm{Gln})$ is classified as pathogenic by UniProt Variants, and this classification has been confirmed according to the American College of Medical Genetics and Genomics guidelines [10].

$\mathrm{Hb}$ Murcia is a new clinically silent $\mathrm{Hb}$ variant. Knowledge of the existence of this variant is important because it could interfere with the results of glucose monitoring by CE-HPLC, wherein glycosylated $\mathrm{Hb}$ Murcia co-elutes with $\mathrm{HbAO}$, thus preventing the correct estimation of HbAlc. When the abnormal glycosylated fraction is not separated, HbAlc would be overestimated; therefore, the $\mathrm{HbAlc}$ chromatogram should be carefully re- viewed to detect the possible presence of variants that interfere with the measurement. In such a case, clinicians would have to use other methods for correct quantification and to avoid potentially inappropriate treatments.

\section{ACKNOWLEDGEMENTS}

None.

\section{AUTHOR CONTRIBUTIONS}

González-Fernández B and Nieto JM carried out genetic studies, Nieto-Campuzano J and García-Rocamora D managed the patient and provided the clinical information, Ropero $\mathrm{P}$ wrote the manuscript, and González FA, Villegas A, and Benavente C contributed to the interpretation of the results and revision of the manuscript. 


\section{CONFLICTS OF INTEREST}

No potential conflicts of interest relevant to this paper are reported.

\section{RESEARCH FUNDING}

None declared.

\section{ORCID}

Beatriz González https://orcid.org/0000-0003-1083-866X José Bartolomé Nieto Campuzano https://orcid.org/0000-0001-7932-6713

Dolores García Rocamora

https://orcid.org/0000-0002-6743-9515

Jorge M. Nieto https://orcid.org/0000-0001-9075-7100

Fernando Ataúlfo González Fernández

https://orcid.org/0000-0003-0663-1666

Ana Villegas

https://orcid.org/0000-0003-3316-8953

Celina Benavente Cuesta

https://orcid.org/0000-0002-0735-2602

Paloma Ropero

https://orcid.org/0000-0002-5126-5039

\section{REFERENCES}

1. Bunn H Franklin, Forget Bernard G. Ed. John Dyson. Hemoglobin: Mo- lecular, Genetic and Clinical Aspects. 2nd Edition. Philadelphia: W.B. Saunders Company, 1986.

2. Pratumvinit B, Reesukumal K, Hanyongyuth S, Wangchaijaroenkit S, Pooliam J, Kost GJ, Kamkang P, Loh TP.Pratumvinit B, et al. Hemoglobin A1c levels are slightly but significantly lower in normoglycemic subjects with the hemoglobin E phenotype. Ann Lab Med 2019;39:209-13.

3. Torrejón MJ, Ortíz-Cabrera NV, M Nieto J, González Fernández FA, Villegas A, Martínez R, et al. Hb Moncloa: A new variant of haemoglobin that interferes in the quantification of $\mathrm{Hb}$ Alc. Clin Biochem 2017;50: 521-24.

4. Oribe Y, Hamaguchi K, Kusuda Y, Harano K, Iwasaki Y, Kotegawa K, et

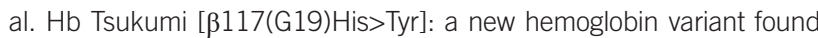
in a Japanese male. Hemoglobin 2000;24:117-23.

5. Ohba Y, Hasegawa Y, Amino H, Miwa S, Nakatsuji T, Hattori T, et al. Hemoglobin Saitama or $\beta 117$ (G19) His leads to Pro, a new variant causing hemolytic disease. Hemoglobin 1983;7:47-56.

6. Di lorio EE, Winterhalter KH, Wilson K, Rosenmund A, Marti HR. A Swiss family with hemoglobin P Galveston $\beta 117$ His leads to Arg, including two patients with Hb P/ $\beta$-thalassemia. Blut 1975;31:61-8.

7. Henthorn JS, Mantio D, Davies SC, Riou J, Wajcman H, Prome D, et al. $\mathrm{Hb}$ Brent [B117(G19)His>Asn]: a new hemoglobin variant found during routine antenatal screening. Hemoglobin 1999;23:89-93.

8. Waye JS, Walker L, Nakamura LM, Eng B, McFarlane A. Hb North York [ $\beta 117(G 19) H i s>A s p]$ : a new $\beta$ chain hemoglobin variant. Hemoglobin 2009;33:51-3.

9. Blanchette M, Kent WJ, Riemer C, Elnitski L, Smit AFA, Roskin KM, et al. Aligning multiple genomic sequences with the threaded blockset aligner. Genome Res 2004;14:708-15.

10. Richards S, Aziz N, Bale S, Bick D, Das S, Gastier-Foster J, et al. Standards and guidelines for the interpretation of sequence variants: a joint consensus recommendation of the American College of Medical Genetics and Genomics and the Association for Molecular Pathology. Genet Med 2015;17:405-24. 